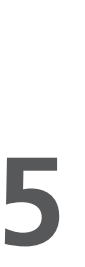

\title{
Evaluation of Women's On-Farm Trial of Drought Tolerant Maize in Southern Guinea Savannah Agro-Ecological Zone of Nigeria
}

\author{
O. E. Ayinde, T. Abdoulaye, G. A. Olaoye, \\ and A. O. Oloyede
}

\subsection{Introduction}

The importance of food security in Africa cannot be overemphasized. This is seen in the growing discussions and efforts made in meeting the food security challenge such as the translation from Millennium Development Goals (MDGs) to Sustainable Development Goals (SDGs). To solve the food security challenge, there is a need to increase agricultural production through technological innovations to boost production in Africa. However, this must be achieved against a backdrop of issues such as climate change and droughts amongst others (Global Food Security Index 2015). Drought is the most devastating and costly challenge to crop production because farmers in Africa practise rain-fed

O. E. Ayinde $(\varangle) \bullet$ G. A. Olaoye $\bullet$ A. O. Oloyede

University of Ilorin, Ilorin, Nigeria

T. Abdoulaye

International Institute of Tropical Agriculture, Ilorin, Nigeria

(C) The Author(s) 2018 
agriculture (Ayinde et al. 2016). Many farmers in Africa are faced with significant reduction in yield due to drought. Fisher et al. (2015) stated that yield losses of about $10-25 \%$ are recorded from around $40 \%$ of Africa's maize-growing areas due to drought stress. It is estimated that by 2030 drought and rising temperatures could render Africa's maizegrowing areas unsuitable for current varieties (CGIAR Big Facts). In addition, it is expected that by 2050 population growth and changing diet will resultantly increase the demand for maize in the developing countries double fold (CIMMYT and IITA 2015). There is also a prediction of an annual $1.3 \%$ growth rate in demand for human consumption of maize in the developing world until 2020 (Ortiz et al. 2010).

This has implications to sub-Saharan Africa, where an array of factors contributes to a sharply increasing demand for maize, including maize being a staple food for an estimated $50 \%$ of the population (Olaniyan 2015) and its importance in addressing the issues related to food security and economic wellbeing. Maize is the most widely grown crop and in terms of food security, it is the most important cereal crop in sub-Saharan Africa (Olaniyan 2015, IITA). Out of 53 countries in sub-Saharan Africa, 46 grow maize. For instance, Nigeria has the largest land area under maize production (seventh in the world and $2.4 \%$ of the total land area) and ranks amongst the top producers (FAOSTAT 2010). Bamire et al. (2010) indicated that maize production in Nigeria is of strategic importance for food security and the socio-economic stability of the country and sub-regions in sub-Saharan Africa. However, recurring droughts has been a continuous challenge to the production of this important crop by drastically reducing yields and livelihoods. Report has it that around $25 \%$ of the maize crop suffers frequent drought, with losses of up to half the harvest in the country (CIMMYT 2013). As a result, new maize varieties will have to be developed quickly and growing in farmers' fields in the next few years if we are to avoid widespread famine in Africa (CGIAR Big Facts).

In a response to these challenges, the Drought Tolerant Maize for Africa (DTMA) project has made releases of 160 DT maize varieties, between 2007 and 2013 (Fisher et al. 2015). The International Institute of Tropical Agriculture (IITA) and International Maize and Wheat Improvement Center (CIMMYT) have been the leading force in DT 
maize variety research in Nigeria (Ayinde et al. 2016). The DT maize varieties, which have demonstrated superiority for grain yield, have been selected annually for testing under farmer's growing conditions in the northern and southern guinea savanna zones of the country. Ayinde et al. (2013) stated that the use of DT maize varieties stabilize maize yields in drought prone ecologies in the country. The development, dissemination and adoption of DT maize varieties, therefore, have the potential of reducing vulnerability and food insecurity (Bamire et al. 2010).

Central to these are the small-scale, resource-poor farming households living in the more marginal rain-fed agricultural areas. In Nigeria, agriculture is predominantly in the hands of rural smallholder farmers who are responsible for more than $70 \%$ of the agricultural production in the country (Enete and Amusa 2010). According to African Development Bank (AFDB) (2015), women constitute almost 50\% of the agricultural labour force, yet they receive a significantly lower share of income with an estimated rural wage gap of $15-60 \%$ between men and women in the same sub-sector.

Despite women's contribution to agriculture, the rural economy and food security in the country, their ability to obtain agricultural inputs is directly constrained by gender discrimination (Simonyan et al. 2011). Soyemi (2014) stated that in a bid to increase productivity of rural farmers in the country, agricultural policies and programmes have focused on development and transfer of appropriate technologies. However, the constraint to such an approach especially for women farmers are that most agricultural technologies are being designed on the assumption that farm managers are men (Simonyan et al. 2011). In addition, even when women own the land, they tend to have limited access to financing, quality inputs, extension services and knowledge of agricultural practices. Ajadi et al. (2015), Soyemi (2014), Adeyemo et al. (2015), and Koyenikan and Ikharea (2014) found that women had less access to agricultural resources and information on agricultural technologies. Beuchelt and Badstue (2013) in a study emphasized that the reduction of gender disparities and the empowerment of women leads to better food and nutrition security for households and significantly strengthens other development outcomes such as child education.

It is therefore necessary for farmers to have access especially to agricultural technologies as this will contribute to both food security and economic 
growth. One of the ways to creating access to agricultural technologies and innovations is the on-farm trial method. On-farm trial is a farming systems approach which includes farmers' participation and helps farmers gain access to new technology earlier, improves farmers' knowledge and experience and encourages feedback between farmers and researchers that can allow for modifications as the growing season progresses. The method also improves farmers' capacity and expertise for conducting collaborative research and can encourage wider adoption of the technology. However, there has been lesser participation of women in on-farm trials. Women's involvement in on-farm trials has been limited and they have been left out of decision-making and evaluation of trials as well as related training (Lahai 1994). In a study in Sierra Leone, Lahai (1994) found that the focus of the extension instructor for the on-farm trials was on the women's husbands despite the fact that the women contributed significantly to the labour for the on-farm research. Saito et al. (1994) also noted that new technology may not be adopted because of the failure to adequately involve women in technology design and implementation. This study is therefore designed to evaluate women's on-farm trial of DT maize varieties in Southern Guinea Savannah zone of Nigeria. According to Norman et al. (1995), evaluation of on-farm trials includes the technological, economic and social analysis. Based on this, the specific objectives of the study are to identify women farmers' preference and evaluate the profitability of the women farmers in new variety production. Women's integration in the testing of agricultural technological innovation such as DT maize has to be examined to enhance gender equity in the use of agricultural technology (DT maize) so as to improve adoption and productivity. Consequently, a gender-balanced agricultural growth is critical to increases in food security and attainment of the SDGs (Ayinde et al. 2012).

\subsection{Materials and Methodology}

\subsubsection{Description of Experimental Materials}

Ten DT open pollinated varieties (OPVs) of maize were tested in farmers' fields in Kwara, Niger and Oyo states of the southern guinea savannah 
(SGS), using on-farm trial approach through women groups. A total of ten kilograms of seeds were distributed among the farmers. The seeds of the improved DT OPVs were provided by IITA to the participating farmers. Furthermore, apart from the on-farm trial, approximately five kilograms of seeds were distributed to women as seed drop to promote production of DT maize varieties.

\subsection{Method}

Seven villages were selected for study. Four villages out of the selected villages had participated in the DT on-farm trial before while the remaining three villages were new. Sensitization was done through visits to the villages. Several meetings were held with the women in the selected villages and collaborators (scientists) from Agricultural Development Projects (ADP) extension agents were in attendance. The purpose for this was proper briefing on the objectives, scope and modality for executing the activities of the project. Women groups were formed in each of these villages: Mokwa, Kishi, Omupo, Lajiki, Arandun, Ballah and Isanlu Isin. This makes a total of seven groups. Each group consists of a minimum of 10 members and a maximum of 20 members. This was done for effectiveness in communication within the groups.

The women groups were trained on correct agronomic practice to enable them understand how to carry out the on-farm trials. The advantages of DTMA were highlighted to the participating women farmers. A plot was marked out for each group for on-farm trials. The plot size for the on-farm trials which included two DT maize varieties and a farmer's variety (sandwiched between the two DT varieties) as check was $10 \mathrm{~m} \times 10 \mathrm{~m}$. Maize was planted at an intra-row spacing of $50 \mathrm{~cm}$ on $75 \mathrm{~cm}$ wide ridges. The fields were kept weed free by the farmers while NPK Fertilizer was applied as split dosage at 4 and 7 Weeks After Planting (WAP) respectively using the recommended dosage in each zone.

The women groups were given extra seeds to plant on their individual farms. Seeds were also given to women who were not part of the group but who were interested at some of the selected villages. Two monitoring tours were undertaken to each farming community during the year. These 
were at the vegetative and flowering phases of the crops, respectively. The visit at the vegetative phase was to further explain the details of the protocols to ensure compliance to the details in the protocols and to collect data at this growth stage. The visit at the flowering phase was essentially for data collection at this phase. Collection of crop performance data from the on-farm trials was undertaken in conjunction with scientists and participating farmers especially during the flowering period. Data were collected essentially on yield parameters. Two estimates of yield (i.e. based on cob and seed yields) were obtained. Ears per plant (EPP) was estimated as a proportion of number of cobs harvested to total harvestable plants while seed to cob yield ratio was expressed as a proportion of yield estimated from cob and seed yield, respectively. Other socioeconomic data were collected through questionnaires.

The sampling technique consists of a two-stage stratified sampling. At the first stage, eight women farmer groups were selected. The second stage involved a random selection of ten women farmers per group per location (village). The total number of farmers selected was 80 .

\subsubsection{Analytical Technique}

Data collected from the trials were analysed. The analytical techniques used include descriptive statistic, ranking method and farm budgeting tool. Descriptive statistic such as frequency, averages, mode, mean and ranking technique which involved the use of a 3-Likert scale to analyse the socio-economic characteristics of the women farmers and their preference scores in the study area. Farm budgeting analysis was used to analyse the profitability of the DT maize varieties in the study area.

\subsubsection{Farm Budgeting Analysis}

The Gross margin analysis was used. Input quantities, factor prices, physical output and gross returns were used. Since the fixed cost constitutes a negligible portion of the total costs of production, the gross margin analysis was employed and used. It is given as: 


$$
\mathrm{GM}_{j}=\mathrm{TR}_{j}-\mathrm{TVC}_{j}
$$

where $\mathrm{GM}_{j}=$ Gross Margin ( $\left./ \mathrm{ha}\right), \mathrm{TR}_{j}=$ Total Revenue ( $\left./ \mathrm{ha}\right)$, $\mathrm{TVC}_{j}=$ Total Variable Cost ( $\left.\mathrm{N} / \mathrm{ha}\right)$

Returns to investment (RI) were also obtained. This was done by dividing gross margin (GM) by the total variable cost of production per hectare. The implicit form is shown below:

$$
\mathrm{GM}_{j}=\mathrm{TR}_{j}-\mathrm{TVC}_{j} \times \frac{100}{1}
$$

where TR and TVC are as defined earlier.

\subsection{Results and Discussion}

\subsubsection{Socio-Economic Characteristics of Women Farmers}

The socio-economic profile of the women farmers is presented in Annex (Table 5.1). The result of the analysis revealed that the average age of farmers in the study area is 43 years with the oldest being 65 years and the youngest 22 years old. This implies that the women farmers are experienced in farming activities. About $23 \%$ of the female farmers were not educated. All the women farmers were married. The female farmers had an average farm size of 1.62 hectares. This implies that the women are less privileged to inputs and less involved in the decision-making process.

\subsubsection{Women Farmer Variety Preference}

Tables 5.2, 5.3, 5.4, 5.5, 5.6, 5.7, and 5.8 in Annex revealed the women farmers preference per location. The women farmers at Lajiki preferred the TZEEI $95 \times$ TZZEE 58 variety than the other varieties. This could be a result of the fast growth and deep green leaf colour of the plant. 
The women farmers at Ballah preferred the TZEEI $81 \times$ TZZEE 95 variety than the other varieties. This could be a result of the attractive look and high vigour of the stands. The result for Arandun showed that the women preferred the EVDT 99 variety the most. The variety was preferred because it has a lot of grain although the cob is small with small seeds than the other varieties and also because EVDT 99 was fast in growth and was able, to some extent, better withstand the climate than the other varieties. The women also indicated that had there been more rain, the variety would have produced better yield. The women group at Omupo and Isanlu Isin preferred the IWDC3 SYN $\times 21$ White DT STR SYN-DT C1 variety than the others. This is due to the fact that the variety had fast growth and was tolerant to drought. The women group at Mokwa preferred the 2013 TZE-W DT STR. This is because the variety had bigger cobs.

\subsubsection{Profitability of On-Farm Trial}

Table 5.9 in Annex shows the profitability of the on-farm trials. The result shows that, at Lajiki, the TZEEI $95 \times$ TZZEE 58 variety gave the highest yield (1560 kg/ha), highest profit of $\$ 33,400$ and highest returns to investment of $90.8 \%$. This implies that for every 1 naira spent, 90 kobo (0.90) was gained as returns. At Ballah, the TZEEI $81 \times$ TZZEE 95 variety produced the highest yield ( $1539 \mathrm{~kg} / \mathrm{ha}$ ), highest profit of 32,985 and the highest $(90.9 \%)$ returns to investment. This implies that the farmers gained 91 kobo (0.91) for every 1 naira spent. At Arandun, the 99TZEE-Y-STR variety produced the highest yield of $2649 \mathrm{~kg} / \mathrm{ha}$, the highest profits of $\$ 81,005$ and the highest returns to investment of $212 \%$. This implies that for every 1 naira used, a return of 2 naira, 12 kobo (2.12) was gained. At Omupo, the IWDC3 SYN $\times 21$ White DT STR SYN-DT C1 variety produced the highest yield of $2630 \mathrm{~kg} / \mathrm{ha}$ and gave the highest profit of 79,650 and highest returns to investment of $205 \%$. This implies that about two naira five kobo (2.05) was gained for every one naira used for production. In general, the DTMA varieties had higher profitability. The DTMA varieties had better yield than the farmers' variety at all locations of the women group trials. 


\subsubsection{Reasons for Preference}

The yellow colour of seed was the most preferred characteristic at all the locations. The yellow maize was preferred whether it was the improved variety or farmer's variety. This is due to the fact that the farmers claimed that the yellow maize was marketable and is of high demand in the market as well as it commands a better price in the market than the white maize. It is also believed that the yellow maize is more nutritious than the white maize. Other reasons for preference include cobs with full grains, big seed, big cobs, DT, big leaves, greenish leaf colour, strongly matured cobs, produce multiple cobs, tall stalks or good stand, high vigour and attractive look.

\subsection{Conclusion and Recommendations}

The study revealed that the women farmer's varietal preference differs across locations. The women farmers ranked the DT maize varieties as the best at all locations. The profitability of the DT maize varieties also differs per location with the DT maize varieties having the highest profit and returns to investment. There was a long period of drought and delayed onset of rainfall (erratic rainfall) which affected the crops and resulted in lower yield than in previous years. However, the successes of the on-farm trial encouraged the women farmers. It is therefore recommended that efforts should be made to involve women farmers in the varietal selection and testing procedure so as to ensure that the women farmers' preferences are incorporated in the development of agricultural technologies. This will help increase the farmers' yield and profitability from their production.

Finally, the study recommends that programmes and policies that will encourage women farmers' involvement in the development and testing of agricultural innovations should be implemented across the country in order to ensure food security and enhanced agricultural productivity. 


\section{Annexes}

Table 5.1 Socio-economic characteristics of women farmers

\begin{tabular}{lcc}
\hline Variables & Frequency & Percentage \\
\hline Age & 22 & 27.5 \\
$<29$ years & 20 & 25.0 \\
30-39 years & 20 & 25.0 \\
$40-49$ years & 14 & 17.5 \\
$50-59$ years & 4 & 5 \\
60 and above & 80 & 100 \\
Total & 43.11 & \\
Mean age & & \\
Marital status & 4 & 5 \\
Single & 75 & 95 \\
Married & 80 & 100 \\
Total & & \\
Level of education & 8 & 10 \\
No formal education & 42 & 52.5 \\
Primary education & 20 & 25 \\
Secondary education & 10 & 12.5 \\
Tertiary education & 80 & 100 \\
Total & & \\
Farm size & 80 & 100 \\
1-5 & 0 & 0 \\
6-10 & 1.92 & \\
Mean & &
\end{tabular}

Table 5.2 Women farmer variety preference result for Lajiki

\begin{tabular}{lllll}
\hline & Low & Medium & High & \\
Variety & Preference (1) & Preference (2) & Preference (3) & Rank \\
\hline TZEEI 95 × TZZEE 58 & 1 & 2 & 7 & 1st \\
TZEEI 81 × TZZEE 95 & 2 & 3 & 5 & 2nd \\
Farmer variety & 9 & 1 & 0 & 3rd \\
\hline
\end{tabular}

Table 5.3 Women farmer variety preference result for Ballah

\begin{tabular}{lllll}
\hline & Low & Medium & High & \\
Variety & Preference (1) & Preference (2) & Preference (3) & Rank \\
\hline TZEEI 95 × TZZEE 58 & 2 & 3 & 5 & 2 nd \\
TZEEI 81 × TZZEE 95 & 0 & 2 & 8 & st \\
Farmer variety & 4 & 5 & 1 & $3 \mathrm{rd}$ \\
\hline
\end{tabular}


Table 5.4 Women farmer variety preference result for Arandun

\begin{tabular}{lllll}
\hline & Low & Medium & High & \\
Variety & Preference (1) & Preference (2) & Preference (3) & Rank \\
\hline EVDT 99 & 0 & 2 & 8 & 1 st \\
99TZEE-Y-STR & 2 & 3 & 5 & 2nd \\
Farmer variety & 4 & 5 & 1 & 3rd \\
\hline
\end{tabular}

Table 5.5 Women farmer variety preference result for Omupo

\begin{tabular}{lllll}
\hline & Low & Medium & High & \\
Variety & Preference (1) & Preference (2) & Preference (3) & Rank \\
\hline IWDC3 SYN $\times 21$ White DT & 0 & 1 & 9 & 1 st \\
STR SYN-DT C1 & & 3 & 7 & 2nd \\
TZ COMPIZDPSYN & 0 & 3 & 3 & 3rd \\
Farmer variety & 4 & & & \\
\hline
\end{tabular}

Table 5.6 Women farmer variety preference result for Isanlu Isin

\begin{tabular}{lllll}
\hline & Low & Medium & High & \\
Variety & Preference (1) & Preference (2) & Preference (3) & Rank \\
\hline IWDC3 SYN $\times 21$ White DT & 0 & 2 & 8 & 1 st \\
STR SYN-DT C1 & & 3 & & \\
TZ COMPIZDPSYN & 1 & 1 & 2 & 2nd \\
Farmer variety & 7 & & & 3rd \\
\hline
\end{tabular}

Table 5.7 Women farmer variety preference result for Mokwa

\begin{tabular}{lllll}
\hline & Low & Medium & High & \\
Variety & Preference (1) & Preference (2) & Preference (3) & Rank \\
\hline 2013 TZE-W DT STR & 0 & 2 & 18 & 1 st \\
2011 TZE-W DT STR SYN & 2 & 4 & 14 & 2nd \\
Farmer variety & 12 & 4 & 4 & 3rd \\
\hline
\end{tabular}

Table 5.8 Women farmer variety preference result for Kishi

\begin{tabular}{lllll}
\hline & Low & Medium & High & \\
Variety & Preference (1) & Preference (2) & Preference (3) & Rank \\
\hline IWD C3 SYN/DT SYN-1-W & 0 & 1 & 9 & 1st \\
2013 DTE STR-W SYN & 1 & 2 & 7 & 2nd \\
Farmer Variety & 6 & 2 & 2 & 3rd \\
\hline
\end{tabular}




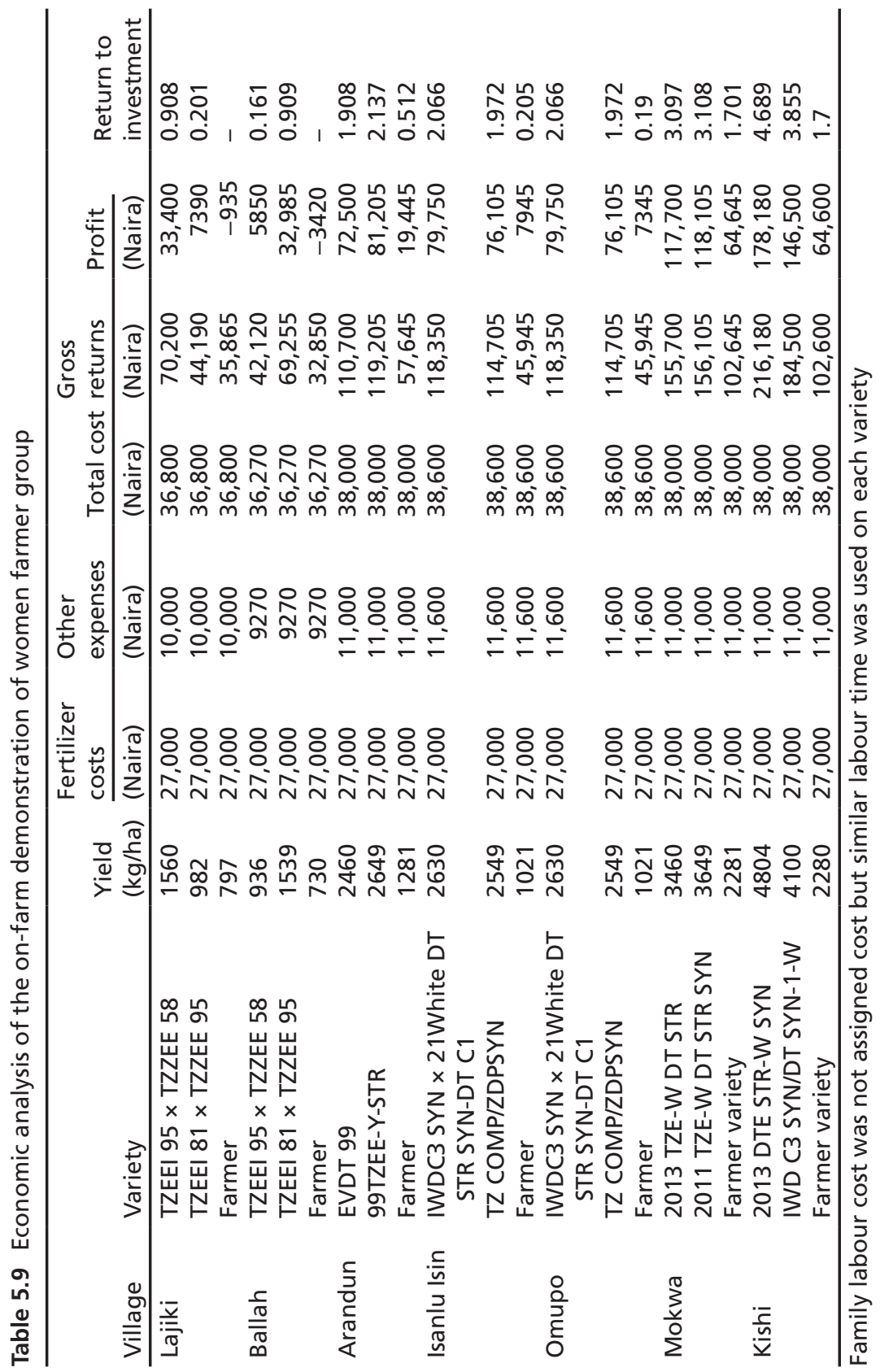




\section{References}

Adeyemo, R., Kirk, M., \& Ogunleye, A. S. (2015). Women Access to Land: The Compatibility of Property Rights on the Farming Activities of Women in Rice Producing Areas of Osun State, Nigeria. International Journal of Research in Agriculture and Forestry, 2(10), 34-42.

AFDB. (2015, August). Economic Empowerment of African Women Through Equitable Participation in Agricultural Value Chains. African Development Bank (AFDB) Report, p. 148.

Ajadi, A. A., Oladele, O. I., Ikegami, K., \& Tsuruta, T. (2015). Rural Women's Farmers Access to Productive Resources: The Moderating Effect of Culture among Nupe and Yoruba in Nigeria. Agriculture \& Food Security, 4, 26.

Ayinde, O. E., Abduolaye, T., Olaoye, G., \& Akangbe, J. A. (2013). Gender and Innovation in Agriculture: A Case Study of Farmers' Varietal Preference of Drought Tolerant Maize in Southern Guinea Savannah Region of Nigeria. Albanian Journal of Agricultural Science, 12(4), 617-625.

Ayinde, O. E., Muchie, M., Adewumi, M. O., \& Abaniyan, E. O. (2012). Risk Analysis of Gender in Innovation System: A Case Study of Production of Downy Mildew Maize Resistant Variety in Kwara State, Nigeria. Obeche Journal, 30(1), 459-465.

Ayinde, O. E., Abdoulaye, T., Takim, F. O., Oloyede, A. O., \& Bankole, F. A. (2016). Economic Analysis of Onfarm Trial of Drought Tolerant Maize in Kwara State Nigeria: A Gender Approach. Trakia Journal of Sciences, 14(3), 287-293.

Bamire, A. S. Abdoulaye, T., Sanogo, D., \& Langyintuo, A. (2010). Characterization of Maize Producing Households in the Dry Savanna of Nigeria. DTMA Country Report-Nigeria.

Beuchelt, T. D., \& Badstue, L. (2013). Gender, Nutrition and Climate-Smart Food Production: Opportunities and Trade-Offs. Food Security, 5, 709-721. CGIAR Big Facts: Evidence of Success Drought-Tolerant Maize Boosts Food Security in 13 African Countries. (n.d.). Retrieved February 2, 2017, from http://CCAFS.CGIAR.ORG/BIGFACTS/. CGIAR Research Program on Climate Change, Agriculture and Food Security (CCAFS).

CIMMYT. (2013, September). The Drought Tolerant Maize for Africa Project. DTMA Brief. http://dtma.cimmyt.org/index.php/about/background.

CIMMYT, \& IITA. (2015). CRP Maize Gender Strategy. CGIAR Research Programme (CRP) on Maize Document, p. 34, CIMMY'T, Mexico. 
Enete, A. A., and Amusa, T. A. (2010) 'Challenges of Agricultural Adaptation to Climate Change in Nigeria: a Synthesis from the Literature', Field Actions Science Reports [Online], Vol. 4, 1-11.

FAOSTAT. (2010). FAO Statistics On-line Database. Retrieved from http://faostat.fao.org/.

Fisher, M., Abate, T., Lunduka, R. W., Asnake, W., Alemayehu, Y., \& Madulu, R. B. (2015). Drought Tolerant Maize for Farmer Adaptation to Drought in Sub-Saharan Africa: Determinants of Adoption in Eastern and Southern Africa. Climatic Change, 133(July), 283-299.

Global Food Security Index. (2015). The Role of Innovation in Meeting Food Security Challenges. Special Report of the Economist Intelligence Unit Limited, p. 18.

Koyenikan, M. J., \& Ikharea, V. E. (2014). Gender Access to and Control of Agricultural Resources in South Zone of Edo State, Nigeria. Journal of Agricultural Economics, Extension and Rural Development, 1(7), 138-145.

Lahai, B. N. (1994). An Evaluation of the Level of Female Participation in Cassava and Sweet Potato On-Farm Trials and Demonstrations in Sierra Leone. Acta Hortic, 380, 55-61.

Norman, D. W., Worman, F. D., Siebert, J. D., \& Modiakgotla, E. (1995). The Farming Systems Approach to Development and Appropriate Technology Generation. Rome: Food and Agriculture Organization of the United Nations. Olaniyan, A. B. (2015). Maize: Panacea for Hunger in Nigeria. African Journal of Plant Science, 9(3), 155-174.

Ortiz, R., Taba, S., Chávez Tovar, V. H., Mezzalama, M., Xu, Y., Yan, J., \& Crouch, J. H. (2010). Conserving and Enhancing Maize Genetic Resources as Global Public Goods-A Perspective from CIMMYT. Crop Science, 50(January), 13-28.

Saito, K. A., Mekonnen, H., \& Spurling, D. (1994). Raising the Productivity of Women Farmers in Sub-Saharan Africa. World Bank Discussion Paper 230, Washington, DC: The World Bank, p. 110.

Simonyan, J. B., Umoren, B. D., \& Okoye, B. C. (2011). Gender Differentials in Technical Efficiency Among Maize Farmers in Essien Udim Local Government Area, Nigeria. International Journal of Economics and Management Sciences, 1(2), 17-23.

Soyemi, O. D. (2014). Women Farmers' Agricultural Information Need and Search Behaviour in North Central Nigeria. Information and Knowledge Management, 4(8). www.iiste.org. 
Open Access This chapter is licensed under the terms of the Creative Commons Attribution 4.0 International License (http://creativecommons.org/licenses/ by/4.0/), which permits use, sharing, adaptation, distribution and reproduction in any medium or format, as long as you give appropriate credit to the original author(s) and the source, provide a link to the Creative Commons license and indicate if changes were made.

The images or other third party material in this chapter are included in the chapter's Creative Commons license, unless indicated otherwise in a credit line to the material. If material is not included in the chapter's Creative Commons license and your intended use is not permitted by statutory regulation or exceeds the permitted use, you will need to obtain permission directly from the copyright holder.

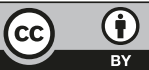

